\title{
Vital root submergence of immature permanent incisors after complicated crown-root fracture followed by orthodontic space maintenance: A presentation of two cases
}

\section{Pozostawienie „zatopionego" korzenia stałych siekaczy z niezakończonym rozwojem po ciężkim złamaniu koronowo-korzeniowym w celu ortodontycznego zachowania miejsca w łuku - opis dwóch przypadków}

\author{
Adrian Strzecki ${ }^{1, A, D}$, Agnieszka Bruzda-Zwiech ${ }^{2, B-C}$, Renata Filipińska ${ }^{2, B, E}$ \\ ${ }^{1}$ Department of Orthodontics, Medical University of Lodz, Poland \\ ${ }^{2}$ Department of Pediatric Dentistry, Medical University of Lodz, Poland \\ A - research concept and design; $\mathrm{B}$ - collection and/or assembly of data; $\mathrm{C}$ - data analysis and interpretation; \\ $D$ - writing the article; $E$ - critical revision of the article; $F$ - final approval of the article
}

Address for correspondence

Adrian Strzecki

E-mail: adrian.strzecki@gmail.com

Funding sources

None declared

Conflict of interest

None declared

Received on October 29, 2017

Reviewed on November 9, 2017

Accepted on January 24, 2018

\begin{abstract}
Complicated crown-root fractures are considered rare occurrences in young permanent dentition; however, they pose a particularly difficult clinical challenge, especially when the traumatized tooth is immature.

Two cases of complicated crown-root fractures of immature incisors are presented. In both cases, vital root submergence with no treatment to the exposed pulp was introduced as a stage in a complex treatment plan with the primary goal of preserving the shape of the alveolar ridge in the traumatized area until the root was completely formed or facial growth was finished. No inflammatory symptoms were detected either radiographically or clinically during the 15- and 16-month follow-up periods. In the chosen clinical cases, vital root submergence followed by orthodontic space maintenance can be beneficial to young patients if other treatment options are limited by the depth of the crown-root fracture or if the patient suffers from high dental fear and presents a particularly low level of compliance.
\end{abstract}

Key words: dental trauma, crown-root fracture, vital root submergence

Słowa kluczowe: uraz zęba, złamanie koronowo-korzeniowe, pozostawienie zatopionego korzenia

DOI

$10.17219 / \mathrm{dmp} / 83744$

Copyright

() 2018 by Wroclaw Medical University

and Polish Dental Society

This is an article distributed under the terms of the

Creative Commons Attribution Non-Commercial License

(http://creativecommons.org/licenses/by-nc-nd/4.0/) 


\section{Introduction}

Traumatic dental injuries (TDI) in patients in developmental age are considered a particularly difficult challenge, as the prognosis regarding tooth vitality is usually poor and the results of dental management difficult to predict. Clinicians need to make the correct clinical decision as quickly as possible while considering its life-long consequences. The early loss of a tooth prior to the pubertal growth spurt can have profound social, aesthetic, occlusal and functional consequences, ${ }^{1-3}$ as the alveolar ridge in the traumatized, post-extraction areas ceases to develop and bone atrophy begins. Although the bone loss of the alveolar ridge is most significant in the horizontal aspect, vertical bone loss also occurs, with the buccal side of the alveolar ridge being most prone to resorption. ${ }^{4,5}$ As a result, the alveolus is reduced, becomes more narrow and more lingually proclined. ${ }^{6}$ What is of major concern in early adolescence is permanent anterior maxillary tooth loss due to alveolar bone arrest and aesthetic ridge deformation, which preclude the insertion of osseointegrated implant with a good emergence profile that is impossible to achieve without ridge augmentation. ${ }^{7,8}$

The central maxillary incisors are the teeth most likely to be injured, and account for $80 \%$ of all traumatized teeth. ${ }^{1}$ Maxillary lateral incisors and mandibular incisors are vulnerable to injury to a lesser extent. ${ }^{1}$ Crown-root fracture defined as a fracture involving enamel, dentin and cementum accounts for $5 \%$ of all dental traumata to permanent dentition, ${ }^{1}$ with transverse fractures being observed less frequently, ${ }^{9}$ especially in children ${ }^{10,11}$ and when the root development is incomplete. ${ }^{10}$ The fracture line can also expose the pulpal tissue, thus dividing the crown-root fracture into 2 groups: complicated and uncomplicated. Treatment options in cases of complicated crown-root fractures are complex, and require a multidisciplinary approach, ${ }^{12}$ the choice of which largely depends on the position and direction of fracture line, pulpal involvement, tooth maturity, and the length of root remaining in the alveolus. ${ }^{2,3,13}$ Even when the fracture is positioned subgingivally, bacterial invasion should be expected to the fracture region, leading in most cases to subsequent inflammation. ${ }^{1,14}$ For this reason, most treatment protocols of deep crown-root fracture require removal of the coronal tooth fragment; however, it can be used for further prosthetic tooth reconstruction.

The treatment modalities described in previous studies can be divided into 2 groups: surgical and conservative. Surgical methods other than extraction focus on the immediate reposition of the intra-osseus tooth portion followed by endodontic treatment. It can be either intentionally replanted or surgically extruded and fixed in a more favorable, supragingival position. Surgical extrusion can be achieved with or without raising the mucoperiosteal flap. The semi-conservative approach involves gingivectomy and osteotomy in order to alter the spatial relations between the alveolar margin and remaining tooth portion. Orthodontic extrusion and submerging vital root portion in situ are procedures burdened with limited invasiveness.

Most case reports describe crown-root fractures occurring in teeth with closed apex or in adult patients. However, most traumatic dental injuries to the permanent dentition occur in schoolchildren. ${ }^{15}$ When the clinician needs to manage crown-root fracture in an immature tooth, treatment modalities are limited by the stage of root development. As presented above, although a plethora of treatment options can be mentioned, almost every one of them requires non-delayed, permanent obturation of the root canal system at one of the clinical stages. For this reason, traumatized developing teeth with open apices are particularly challenging to clinicians, especially when the fracture line is located subgingivally. According to current guidelines regarding traumatic dental injuries (TDI) management, ${ }^{15}$ "every effort should be made to preserve pulpal vitality in the immature permanent tooth to ensure continuous root development". Young age restricts the range of available treatment modalities, both due to the stage of root development and the limited level of patient compliance. Hence, in young children with immature permanent teeth demonstrating crown-root fracture, the main focus should be on choosing methods with minimal invasiveness to the surrounding bone and periodontium, retaining the ability of the root to continue its development and preventing the early loss of the tooth, thus preserving the height and width of the alveolus in the traumatized site, negating the possible consequences of the injury to the occlusion and providing a temporary aesthetic solution to minimize the social problems encountered by the child. The aim of this article is to present 2 cases of subgingival crown-root fracture of immature teeth treated by a minimally invasive multidisciplinary treatment approach which can be also introduced in patients with a high level of dental fear.

\section{Case presentation}

\section{Case 1}

A 10-year-old male patient was referred to the Department of Pediatric Dentistry of our institution due to a dental injury suffered the previous evening after falling from a chair. His medical history was not relevant. Clinical examination revealed a fractured restoration of the medial corner of the left upper central incisor, as well as movable composite build-up of the left lateral incisor with marginal gum swelling and bleeding. Tooth \#22 was very tender to percussion and the lower lip was swollen. The prior dental history revealed that he had suffered trauma to the same maxillary region 6 months before, 
diagnosed as uncomplicated crown fracture of teeth \#11 and \#21, and uncomplicated crown-root fracture of tooth $\# 22$, with an oblique fracture line penetrating subgingivally. The teeth underwent immediate conservative restoration with no further complications. The second trauma led to a crown-root fracture of the lateral left incisor as the mobile composite reconstruction was attached to the fractured crown portion. The fracture line was horizontal and reached below the alveolar ridge margin. A radiographic examination confirmed the diagnosis of a crown root fracture with pulp exposure and additionally showed incomplete root development of tooth \#22 (Fig. 1a). After a holistic assessment of clinical and radiographic findings, the decision was made to perform in situ submergence of the vital root fragment. The coronal part of tooth \#22 was surgically removed under local anesthesia, and the fracture margin was exposed. The root fragment with the bleeding exposed pulp was gently rinsed with $0.9 \%$ saline, and the gingival tissue was soundly sutured. Antibiotic therapy with $150 \mathrm{mg}$ clindamicine administered 4 times a day was prescribed.

This clinical decision had the following rationale: 1 . as the crown root fracture occurred at the level of the alveolar ridge, the remaining apical portion of injured tooth \#22 did not reach the criteria of 1:1 crown-root ratio and so could barely support a future permanent prosthetic build-up; gingivectomy/osteotomy with subsequent apexification or mineral trioxide aggregate (MTA) pacement in apical region and root canal obturation, followed by orthodontic extrusion would not alleviate this problem; 2 . due to the patient's young age, extraction of the remaining root fragment would lead to severe alveolar atrophy in anaesthetically-sensitive region. The root was submerged with the intention of retaining the shape of the alveolar process for as long as possible, preferably until the facial growth was finished and a dental implant could be placed in the traumatized area. After 2 weeks of uneventful healing, the sutures were removed (Fig. 1b, c). Subsequently, the orthodontic
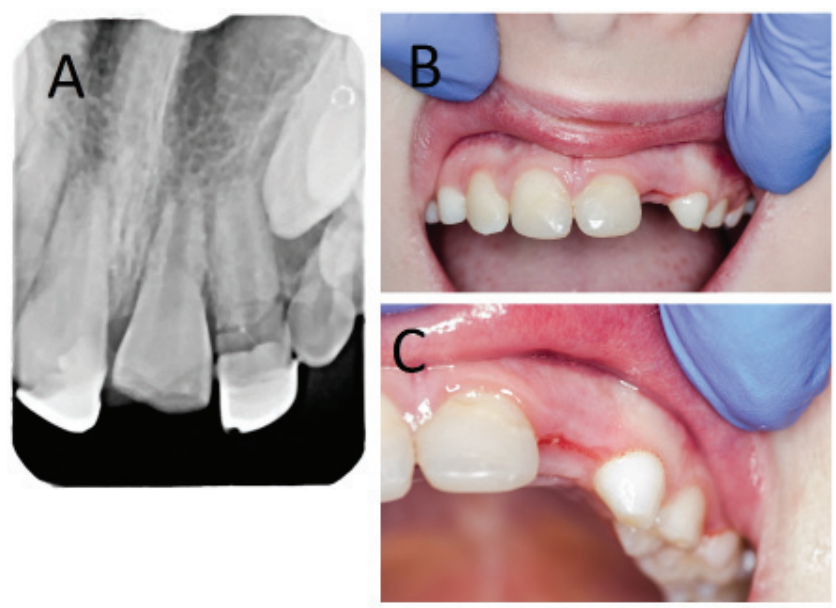

Fig. 1. A - radiograph taken at the day of trauma - crown root fracture of the upper left lateral incisor (\#22). B, C - upfront view of traumatized area after 2 weeks of healing and suture removal
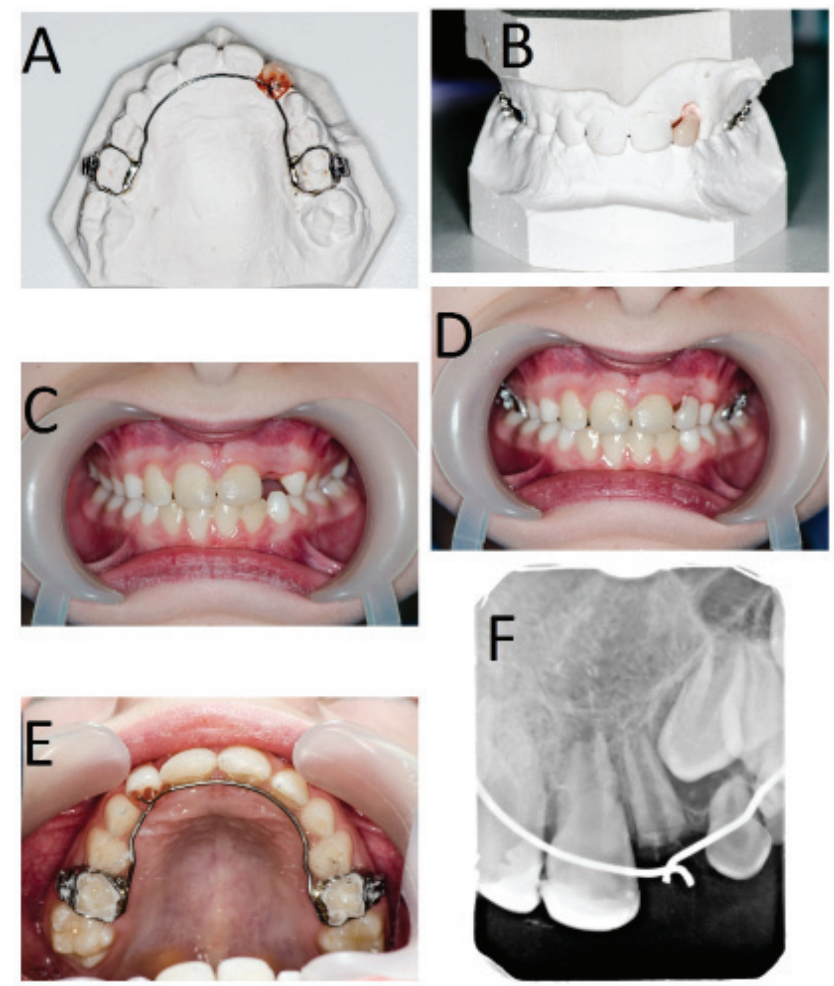

Fig. 2. A, B - upper lingual arch with acrylic tooth \#22 on the dental cast. Orthodontic bands fitted on the upper second deciduous molars. C - upfront view of patient's anterior dentition without the prepared appliance. D, E - patient's dentition with the cemented lingual arch: upfront (D) and palatal view (E). F - dental radiograph taken after the placement of orthodontic appliance -4 weeks after the trauma

bands were fitted to the deciduous upper second molars and dental impressions were taken to restore the missing crown of tooth \#22 by the use of an upper lingual arch with an attached acrylic tooth (Fig. 2a, b). The patient did not have any orthodontic treatment needs besides the insertion of a space retainer after the dental trauma, and his first permanent molars were in I Angle Class intercuspidation on both sides of the dental arch. The lingual arch was cemented on the next dental visit with satisfactory aesthetic and functional effect (Fig. 2c-f). As the oral hygiene of the patient was sub-optimal, the deciduous second molars were chosen as a support for the lingual arch instead of the permanent first molars to protect the latter from the increased risk of caries associated with the presence of orthodontic bands. Therefore, the mentioned appliance should be perceived as a long-term solution, but not a permanent one: after root resorption occurs in the deciduous second molars, the lingual arch will be modified and fitted to the permanent first molars. No inflammatory symptoms could be detected either clinically or radiographically at any stage of treatment or during a 13-month follow-up (Fig. 3a). The submerged root manifested continued development. Although the shape of the alveolar ridge slightly altered vertically, the bone loss was not significantly pronounced in the horizontal aspect (Fig. 3b-d). The orthodontic appliance was well tolerated by the patient, who underwent check-ups every 6 weeks. 

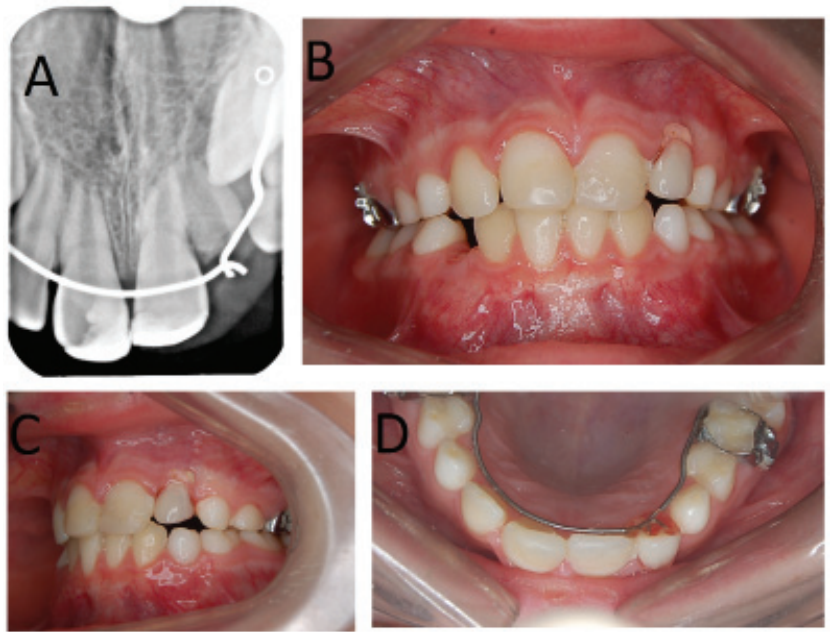

Fig. 3. A - dental radiograph taken after 13-month follow-up period. No inflammatory symptoms could be detected. B-D - bone loss in the injured area appears to be only slightly pronounced in vertical aspect and the overall esthetic outcome is satisfactory

After 15 months from trauma, the upper second deciduous molars became mobile due to the physiological root resorption and additional occlusal load connected with supporting the artificial crown of the tooth \#22. The appliance was removed and the patient was referred to the surgical clinic to have teeth \#55 and \#65 extracted. Clinical examination revealed the retained shape of alveolar process with slightly pronounced vertical bone loss (Fig. $4 a-b)$. No inflammatory symptoms could be observed (Fig. $4 \mathrm{a}-\mathrm{c}$ ). Closed root apex with no signs of chronic periapical inflammation can be observed on the dental radiograph taken during the appointment (Fig. 4d). The patient was highly anxious towards the planned surgical procedures and both his compliance and oral hygiene
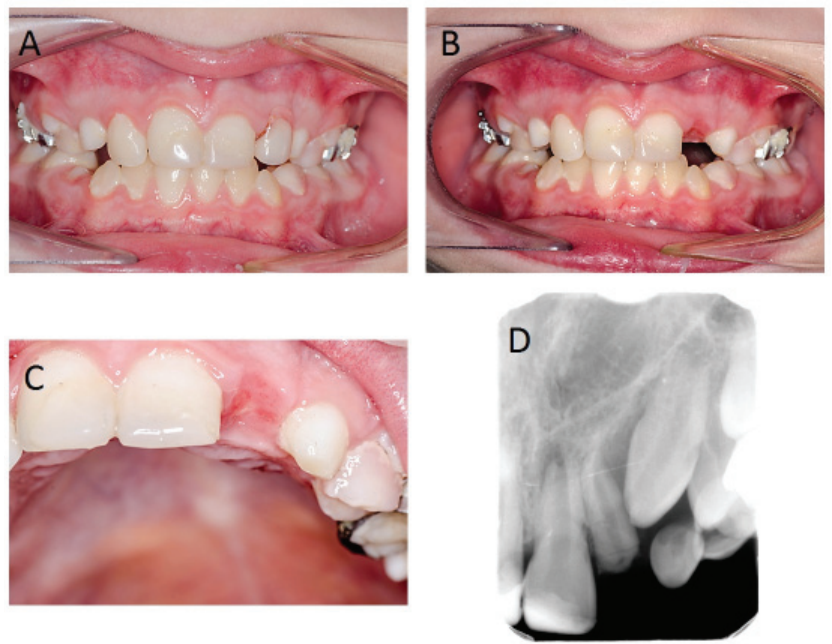

Fig. 4. A, B - patient after 15-month follow-up period with and without the attached acrylic tooth \#22. Slight inflammation of the mucosa observed in the injured region can be attributed to the poor oral hygiene combined with the contact with the acrylic resin. C - the bone loss in the horizontal aspect can be hardly observed. D - dental radiograph taken after 15-month follow-up period: apex of the root of the tooth \#22 is closed; previously exposed pulp area is covered with radiopaque tissue were unsatisfactory. Certain clarification of the observed situation was given, with the parents mentioning that our patient was recently diagnosed with Asperger's syndrome. The treatment focusing on retaining the space after the lost tooth \#22 was continued by means of removable orthodontic appliance (modified Schwarz-type expander) with the attached acrylic crown.

\section{Case 2}

An 8-year-old female patient was referred to the Department of Pediatric Dentistry of our institution for traumatic dental injury suffered the previous day at school. The medical history was non-contributory. The maxillary anterior region was most severely injured, with the right central incisor subluxated and left central incisor crown horizontally fractured at the level of the alveolar ridge (classified as crown-root fracture with pulp exposure). The clinical examination also revealed poor oral hygiene and many carious lesions requiring immediate treatment. Tooth \#21 was not visible in the mouth, and the dental socket in the site of the tooth was filled with a blood clot (Fig. 5b). The fractured coronal tooth fragment, brought in by the parents, was rinsed with $0.9 \%$ saline and stored in saline at $4^{\circ} \mathrm{C}$ for possible future adhesive build-up. The parents also provided clinicians with a dental radiograph taken on the day of the trauma; however, it did not show the whole apical region of tooth \#21 (Fig. 5a). Tooth \#11 was subluxated and manifested slight pathological mobility, along
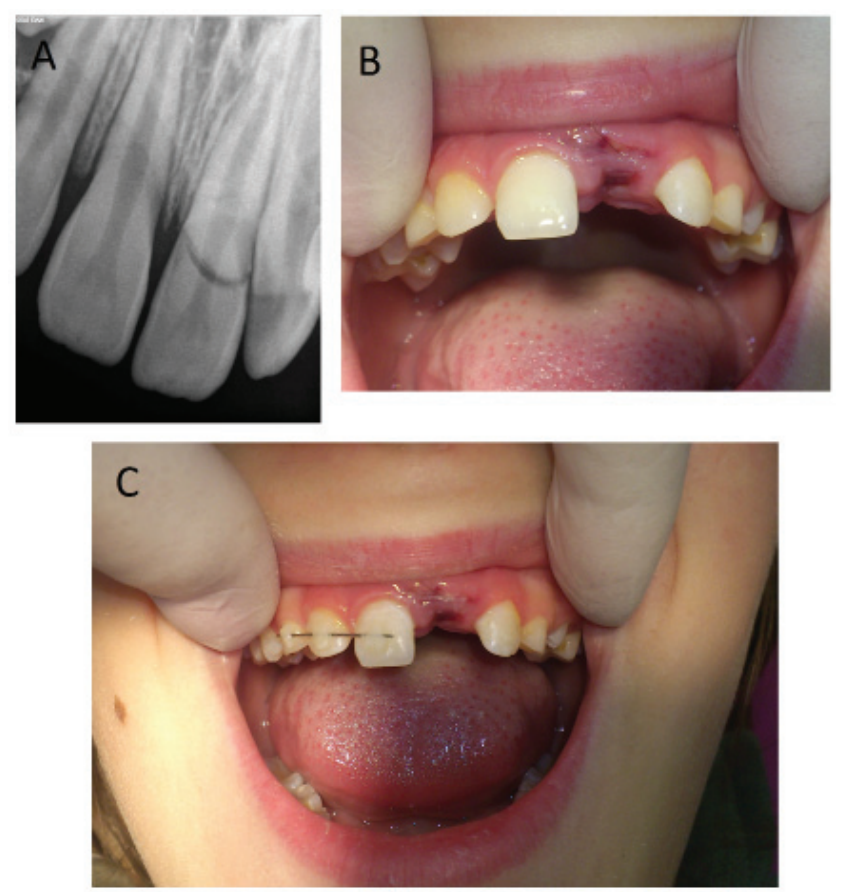

Fig. 5. A - dental radiograph taken at the day of trauma. Tooth \#21 is horizontally fractured at the cervical area. Periapical region of the tooth \#21 cannot be assessed. B - missing clinical crown and the dental socket of the tooth \#21 filled with a blood clot - clinical situation during the first appointment. C - semi-rigid splint connecting the teeth \#11-\#13 applied due to the subluxation of the tooth \#11 

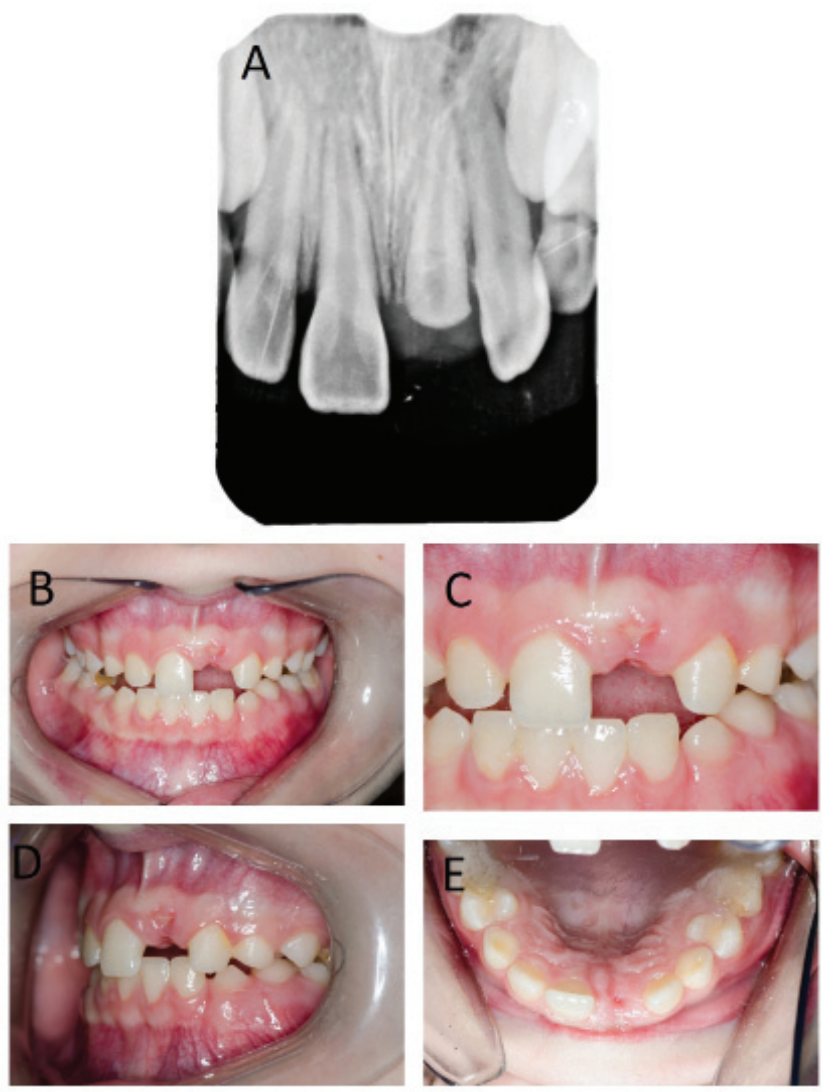

Fig. 6. A - dental radiograph of the injured area taken after 7-week period. No inflammatory symptoms could be detected and the process of the closure of the root apex continued. Note the mineralized tissue covering the area of previously exposed pulp. B-E - view of the patient's dentition after 7-weeks from the dental injury. No inflammatory symptoms could be detected clinically

with tenderness to vertical percussion. The sensitivity of the pulp was positive when tested with a cold stimulus. The subluxated tooth was splinted with semi-rigid wire and composite resin for 2 weeks (Fig. 5c). The anatomic relationship between the fracture line and the alveolar ridge margin could be assessed, despite the parents not giving consent for another dental X-ray to be taken on the day of admission. Although the stage of root formation could not be evaluated, it was assumed on the basis of age of the patient that root development was not completed.

As the length of the root of tooth \#11 seemed to be adequate for supporting post-retained crown reconstruction, immediate gingivectomy or even osteotomy followed by the subsequent MTA placement in apical region of the root to form a hard barrier prior to gutta-percha root obturation were considered. However, this treatment option was abandoned due to dental fear and low level of compliance by the patient. Vital root submergence in situ was discussed with the parents as a treatment option, which might allow for root apex closure of tooth \#22 and the use of an apical fragment for later post-retained crown reconstruction.

The traumatized area with its remaining root segment was rinsed with $0.9 \%$ saline and soundly sutured. After 2 weeks of uneventful healing, the sutures and splint were removed. The patient failed to attend a scheduled check-up visit 4 weeks following the trauma, but did so after 7 weeks, when it was possible to assess the course of the treatment both clinically and radiographically (Fig. 6a-e). No inflammatory symptoms were present at the time of examination and the traumatized region had healed properly. A dental radiograph showed an incompletely closed apex root of tooth \#21, the root portion appeared to be of sufficient length for future core build-up. The area of the previously-exposed pulp appeared to be covered with hard tissue resembling radiographically reparative dentine.

After the apex closure process is completed and patient compliance will be sufficient, it is planned to extirpate the pulp and extrude the root orthodontically above the gingival level, thus enabling a long-term temporary prosthetic build-up. It was also noted that the margin of the fractured root was visible above the mucosa in a very limited area. It is possible that the root either began to spontaneously erupt or the root exposure occurred due to alveolar ridge recontouring. Due to the patient's young age, poor oral hygiene and narrow maxillary arch, it was decided to combine a temporary replacement for the crown of tooth \#21 with treatment using an orthodontic removable appliance. An active palatal plate with an acrylic tooth \#21 and expansion screw positioned in the midline was designed (Fig. 7a-d). After a 10-month follow-up, no inflammatory symptoms could be observed either clinically or radiographically (Fig. 8a-d). The apexification of the submerged root continued, thus indicating that the pulp retains its vitality. The patient showed improved compliance and was pleased with the esthetics of the proposed clinical solution (Fig. 8e).

Certain difficulties occurred in further monitoring of treatment outcome, as the patient failed to show up for a pre-scheduled appointment at the 12-month stage of follow-up. It was not until 16 months after the trauma when we could get in touch with the patient's parents
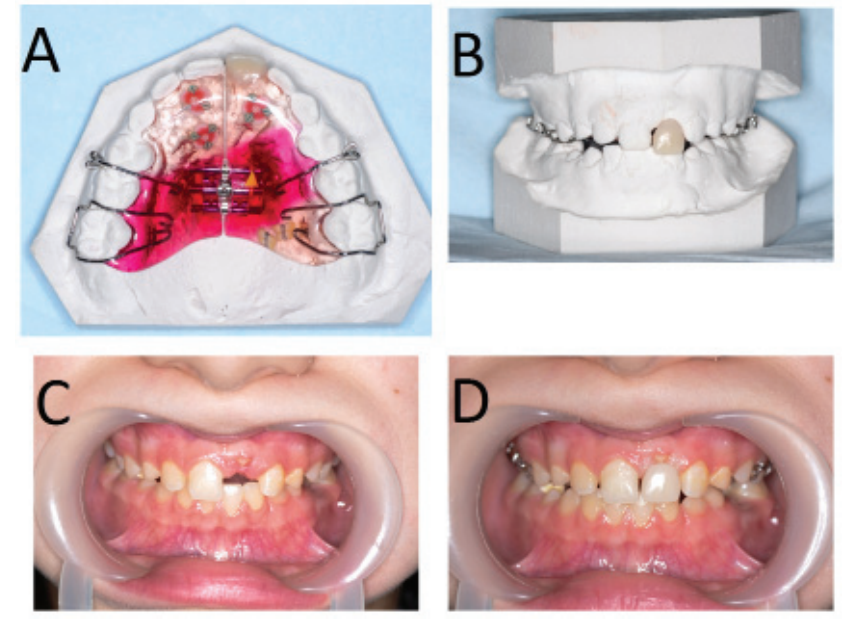

Fig. 7. A, B - removable appliance fitted on the dental cast. C, D - upfront view of patient's anterior dentition without the appliance and with the appliance inserted into the oral cavity 
and the control clinical and radiological examination could be performed. No inflammatory symptoms were either mentioned by the patient or discovered during the check-up (Fig. 9a, b). The crest of the alveolar process in the injured area was on the level of cervical gingival margin surrounding the tooth \#11, which could be described as a major improvement (Fig. 9c). A radiographic examination showed closed root apex of the tooth \#21 with no periapical lesions and the area of previously exposed pulp covered with radiopaque tissue (Fig. 9d). The patient and her parents were reluctant to the proposed plan of the elective endodontic treatment and a subsequent forced orthodontic eruption of the root and wished to continue the treatment with the current appliance. It was established that the treatment options will be re-discussed after the eruption of all premolar teeth, which will necessitate the change of the removable appliance. Nevertheless, sustaining the alveolar bone level and completed closure of the root apex made all of the permanent treatment options ranging from the combined orthodontic and prosthetic treatment to the implant placement possible.
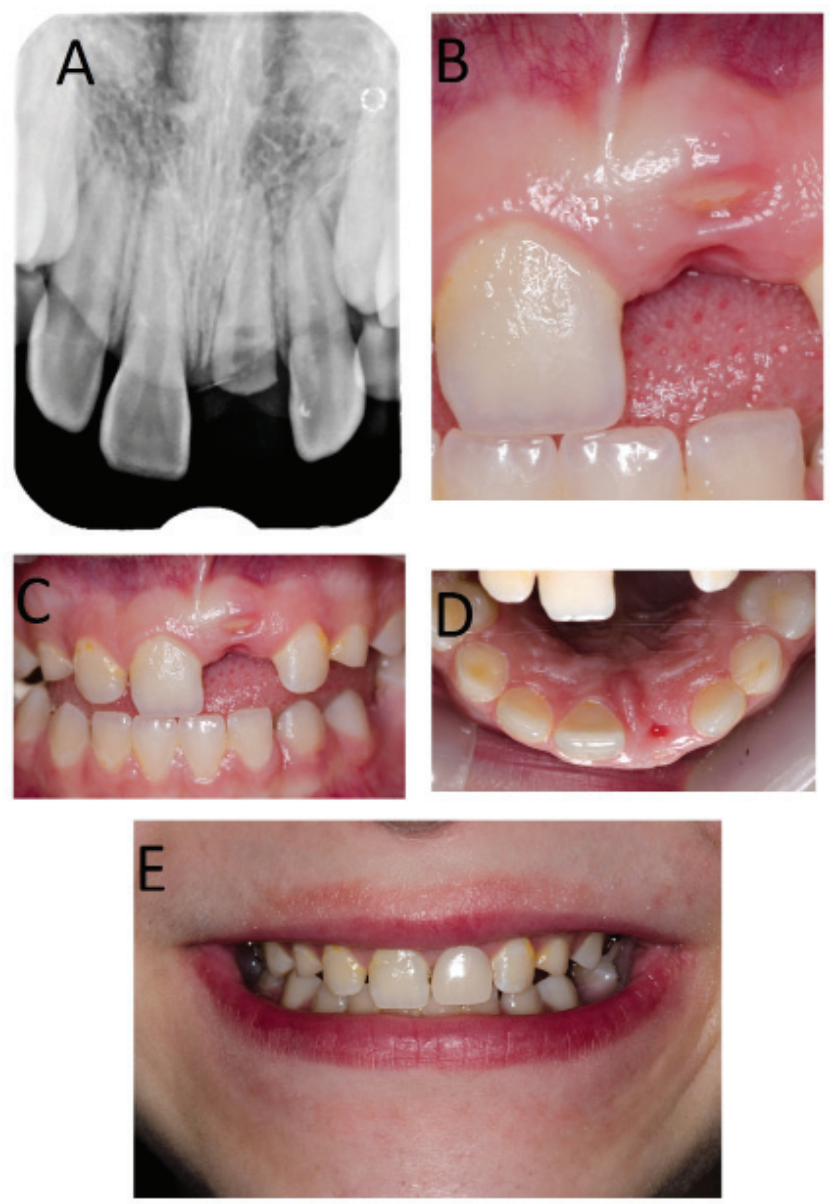

Fig. 8. A - dental radiograph taken after the 10-month follow-up period. The apex of the root of the tooth \#21 is closed and no sign of chronic inflammation could be detected. B-E - 10 months from the injury. No inflammatory symptoms could also be detected during the clinical examination
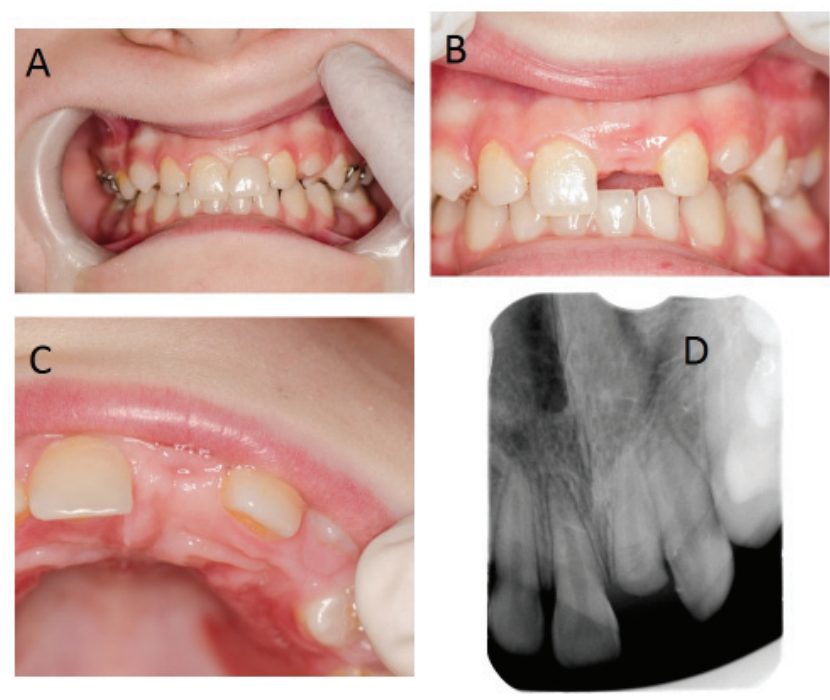

Fig. 9. A-C - clinical examination after 16-months. Both vertical and horizontal dimension of the alveolar ridge remained unchanged. No inflammatory state could be detected. D - dental radiograph taken after 16-month follow-up period: apex of the root of the tooth \#22 is closed; previously exposed pulp area is covered with radiopaque tissue

\section{Discussion}

Although intentional submerging in situ of vital roots after crown-root fracture is mentioned in up-to-date guidelines regarding the management of traumatic dental injuries, ${ }^{15}$ reports of cases presenting it are rarely encountered in scientific literature. A review of existing literature reveals only one such study by Mackie et al. ${ }^{16}$ Although the main advantage of this approach is the possibility of retaining the shape and size of the alveolar ridge in the traumatized region until the facial growth is finished, it also offers limited invasiveness, which requires little compliance, continued root development and no additional iatrogenic trauma to the surrounding tissues. Furthermore, it offers other benefits for the patient in cases when the remaining root cannot support any post-retained crown due to inadequate length and needs to be extracted.

The fact that the untreated, exposed pulp showed no immediate or delayed inflammatory symptoms, either clinically or radiographically, can be expected to a certain extent. This can be probably attributed to the stage of tooth development and relatively good perfusion of pulpal tissue in immature teeth. Furthermore, radiographs taken at various treatment stages indicated that the pulp tissue remained vital. The rationale behind root submergence is derived from studies concerning fractured and retained roots following unsuccessful extractions of vital teeth. The vast majority of studies show that such retained roots remain either vital or uneventful. ${ }^{17,18}$ Some authors suggest that the submerged root can be covered with new bone. ${ }^{19}$ Attempts to preserve the volume of the alveolar ridge by means of vital root submergence in older prosthetic patients, when the crown-root ratio is unfavorable, have also been suggested. ${ }^{20}$ As it was mentioned above, 
the decoronation of deeply impacted lower third molars bears a certain resemblance to the intentional submergence of traumatized roots. Despite obvious differences, both procedures treat the exposed pulp with $0.9 \%$ saline, which is then covered with a tightly sutured mucoperiosteal flap. The most important similarity is, however, the lack of subsequent symptoms of pulp inflammation despite the lack of any capping. Interestingly, in some cases, the passive eruption of retained teeth occurs. ${ }^{21}$

What should, and could, be done with the remaining apical tooth segment is clearly the main problem encountered in crown-root fracture management in the developmental age. The 4 key issues that need to be addressed are as follows: 1 . whether the length of the remaining portion of the root is adequate and whether it may be used after surgical procedures/orthodontic extrusion for fixed prosthesis purposes; 2 . what can be done and achieved at the current development stage of traumatized tooth root and patient growth stage; 3 . the level of patient motivation and compliance and whether the clinician is likely to be limited by technical constraints or adolescent patient cooperation, and finally; 4 . what can be done to protect the height and width of the alveolar process.

When the submergence of the vital root is performed for the preservation of the alveolar ridge prior to permanent prosthetic reconstruction with a dental implant, spontaneous eruption of the root may be regarded as an undesirable complication. ${ }^{22}$ However, in our case of the submergence of a vital root with a length adequate to support further post-retained crown reconstruction, the fact that the root began to erupt can be beneficial, as described in a case presented by Johnson and Jensen, ${ }^{22}$ in which spontaneous eruption eliminated the need for surgical exposure and orthodontic extrusion of the root fragment and allowed for successful root canal obturation and restoration with a post and porcelain fused to metal crown.

In the first of our cases, the possibility of using the root fragment for the prosthetic purposes, even after orthodontic extrusion, would be very limited as the crown to root ratio would be significantly higher than $1: 1$. In the second case, the remaining fragment of the central incisor is sufficient for prosthetic build up and forced eruption is planned. However, in our opinion, prosthetic reconstruction should be delayed, as the root shows no inflammatory symptoms, root development persists and mildly pronounced passive eruption can be observed. After apexification is completed, a forced eruption should be performed, thus enabling at least temporary prosthetic restoration of the fractured crown.

\section{Conclusions}

Vital roots submergence could be considered as the first stage of a more complex treatment scheme in juvenile patients burdened with few possible complications and requiring very low level of compliance. The retained root may remain within the alveolus until the implant placement is possible or serve as a prosthetic post following delayed pulp extirpation. The possibility of delaying pulp extirpation may prove beneficial in certain clinical situations with the emphasis of the immature traumatized teeth. Orthodontic appliances with attached artificial dental crowns prove to be aesthetically acceptable, multi-purpose clinical solutions in cases of early clinical crown loss in growing patients. The root submergence procedure also allows for dental fragments that would otherwise be extracted to remain within the alveolus and at least partially contribute to retaining the shape of the alveolar ridge.

As the pulpal tissue in the submerged roots showed no inflammatory symptoms, despite being left untreated and only tightly covered with mucosa, its immune defensive capabilities in teeth with an open apex may be higher than commonly perceived. For this reason, root submergence is worth considering in young patients experiencing deep crown-root fracture, especially when they suffer from high dental fear and a low level of compliance.

\section{References}

1. Andreasen JO, Andreasen FM, Andersson L. Textbook and Colour Atlas of Traumatic Injuries to the Teeth. $4^{\text {th }}$ ed. Oxford, England: Blackwell Munksgaard; 2007:314-336.

2. Andreasen JO. Etiology and pathogenesis of traumatic dental injuries. A clinical study of 1298 cases. Scand J Dent Res. 1970;78:329-342.

3. Naudi $A B$, Fung DE. Tooth fragment reattachment in multiple complicated permanent incisor crown-root fractures: A report of two cases. Dent Traumatol. 2008;24:248-252.

4. Araujo MG, Lindhe J. Dimensional ridge alterations following tooth extraction: An experimental study in the dog. J Clin Periodontol. 2005;32:212-218.

5. Araujo MG, Lindhe J. Ridge alterations following tooth extraction with and without flap elevation: An experimental study in the dog. Clin Oral Implants Res. 2009;20:545-549.

6. Pinho MN, Roriz VL, Novaes $A B$, et al. Titanium membranes in prevention of alveolar collapse after tooth extraction. Implant Dent. 2006:15:53-61.

7. Darby I, Chen ST, Buser D. Ridge preservation techniques for implant therapy. Int J Oral Maxillofac Implants. 2009;24(Suppl):260-271.

8. Jung RE, Philipp A, Annen BM. Radiographic evaluation of different techniques for ridge preservation after tooth extraction: A randomized controlled clinical trial. J Clin Periodontol. 2013;40:90-98.

9. Fariniuk LF, Ferreira EL, Soresini GC, Cavali AE, Baratto Filho F. Intentional replantation with 180 degree rotation of a crown-root fracture: A case report. Dent Traumatol. 2003;19:321-325.

10. Díaz SC, Ferreyra S, Gutmann JL. Healing of a horizontal root fracture with lateral luxation of the coronal fragment: A 3-year followup ENDO (Lond Engl). 2013;7:291-297.

11. Orhan K, Orhan Al, Tulga F. Management of untreated traumatized permanent incisors with crown and root fractures: A case report. Quintessence Int. 2009;40:647-654.

12. Robertson A. A retrospective evaluation of patients with uncomplicated crown fractures and luxation injuries. Endod Dent Traumatol. 1998;14:245-256.

13. Wang Z, Heffernan M, Vann WF Jr. Management of a complicated crown-root fracture in a young permanent incisor using intentional replantation. Dent Traumatol. 2008;24:100-103.

14. Bevelander G. Tissue reactions in experimental tooth fracture. J Dent Res. 1942;21:481-487.

15. DiAngelis AJ, Andreasen JO, Ebeleseder KA, et al. Guidelines for the management of traumatic dental injuries: 1 . Fractures and luxations of permanent teeth. Dent Traumatol. 2012;28:2-12. 
16. Mackie IC, Quayle AA. Alternative management of a crown root fractured tooth in a child. Br Dent J. 1992;173:60-62.

17. Simpson HE. Histological changes on retained roots. J Can Dent Assoc. 1959;25:287.

18. Glickman I, Pruzansky S, Ostrach M. The healing of extraction wounds in the presence of retained root remnants and bone fragments. Am J Orthod. 1974;33:263.

19. Von Wowern N, Winther S. Submergence of roots for alveolar ridge preservation. Int J Oral Surg. 1981;10:247-250.

20. Sharma A, Oberoi SS, Saxena S. Submergence of vital roots for the preservation of residual ridge: A clinical study. Oral Health Prev Dent. 2012;10:259-265.

21. Renton T, Hankins M, Sproate C, McGurk M. A randomised controlled clinical trial to compare the incidence of injury to the inferior alveolar nerve as a result of coronectomy and removal of mandibular third molars. Br J Oral Maxillofac Surg. 2005;43:7-12.

22. Johnson BR, Jensen MR. Treatment of a horizontal root fracture by vital root submergence. Endod Dent Traumatol. 1997;13:248-250. 